\title{
Oral Route Driven Acute Trypanosoma cruzi Infection Unravels an IL-6 Dependent Hemostatic Derangement
}

\section{OPEN ACCESS}

Edited by:

Soledad Negrotto,

Academia Nacional de Medicina,

Argentina

Reviewed by:

Oscar Campetella,

National University of General San

Martín, Argentina

Bertha Espinoza,

National Autonomous University of

Mexico, Mexico

*Correspondence:

Juliana de Meis

jdemeis@ioc.fiocruz.br

Specialty section:

This article was submitted to Inflammation,

a section of the journal

Frontiers in Immunology

Received: 26 December 2018

Accepted: 26 April 2019

Published: 14 May 2019

Citation:

Antunes D, Marins-Dos-Santos A,

Ramos MT, Mascarenhas BAS, Moreira CJdC, Farias-de-Oliveira $D A$ Savino W, Monteiro RQ and de Meis J

(2019) Oral Route Driven Acute Trypanosoma cruzi Infection Unravels

an IL-6 Dependent Hemostatic

Derangement

Front. Immunol. 10:1073.

doi: 10.3389/fimmu.2019.01073

\section{Dina Antunes ${ }^{1,2}$, Alessandro Marins-Dos-Santos ${ }^{1,2}$, Mariana Tavares Ramos ${ }^{1,2}$, Barbara Angelica S. Mascarenhas 1,2, Carlos José de Carvalho Moreira ${ }^{3}$, Désio Aurélio Farias-de-Oliveira ${ }^{1,2}$, Wilson Savino ${ }^{1,2}$, Robson Q. Monteiro ${ }^{4}$ and Juliana de Meis ${ }^{1,2 *}$}

\footnotetext{
${ }^{1}$ Laboratory on Thymus Research, Oswaldo Cruz Institute, Oswaldo Cruz Foundation, Rio de Janeiro, Brazil, ${ }^{2}$ National Institute of Science and Technology on Neuroimmunomodulation, Oswaldo Cruz Institute, Oswaldo Cruz Foundation, Rio de Janeiro, Brazil, ${ }^{3}$ Parasitic Diseases Laboratory, Oswaldo Cruz Institute, Oswaldo Cruz Foundation, Rio de Janeiro, Brazil, ${ }^{4}$ Institute of Medical Biochemistry Leopoldo de Meis, Federal University of Rio de Janeiro, Rio de Janeiro, Brazil
}

Oral transmission of Trypanosoma cruzi, the etiologic agent of Chagas disease, is presently the most important route of infection in Brazilian Amazon. Other South American countries have also reported outbreaks of acute Chagas disease associated with food consumption. A conspicuous feature of this route of transmission is presenting symptoms such as facial and lower limbs edema, in some cases bleeding manifestations and risk of thromboembolism are evident. Notwithstanding, studies that address this route of infection are largely lacking regarding its pathogenesis and, more specifically, the crosstalk between immune and hemostatic systems. Here, BALB/c mice were orally infected with metacyclic trypomastigotes of $T$. cruzi Tulahuén strain and used to evaluate the cytokine response, primary and secondary hemostasis during acute T. cruzi infection. When compared with control uninfected animals, orally infected mice presented higher pro-inflammatory cytokine (TNF- $\alpha$, IFN- $\gamma$, and IL-6) serum levels. The highest concentrations were obtained concomitantly to the increase of parasitemia, between 14 and 28 days post-infection (dpi). Blood counts in the oral infected group revealed concomitant leukocytosis and thrombocytopenia, the latter resulting in increased bleeding at $21 \mathrm{dpi}$. Hematological changes paralleled with prolonged activated partial thromboplastin time, Factor VIII consumption and increased D-dimer levels, suggest that oral T. cruzi infection relies on disseminated intravascular coagulation. Remarkably, blockade of the IL-6 receptor blunted hematological abnormalities, revealing a critical role of IL-6 in the course of oral infection. These results unravel that acute T. cruzi oral infection results in significant alterations in the hemostatic system and indicates the relevance of the crosstalk between inflammation and hemostasis in this parasitic disease.

Keywords: Chagas disease, oral transmission, cytokine, platelet, coagulation, interleukin-6 


\section{INTRODUCTION}

The hemoflagellate protozoan Trypanosoma cruzi is the causative agent of Chagas disease or American trypanosomiasis which is transmitted primarily through contact with feces of triatomine insects after biting (1). Transmission can also occur through blood transfusion (2), organ transplantation (3), congenitally (vertical transmission) (4), laboratory accidents (5) and by ingestion of contaminated food/juices $(6,7)$. Currently, oral infection is the most frequent route of transmission in Brazil and other Latin American countries (7-9). Mortality rates in these orally infected patients are higher (8-35\%) when compared with the classical vectorial transmission $(<5-10 \%)(10)$. The acute phase of the disease is a critical period often accompanied by non-specific clinical symptoms, such as fever, asthenia, face and limb edema, headache, myalgia, and others. Minor bleeding manifestations, most commonly from nose, skin petechiae, or bruising, are apparent in some patients with oral acute Chagas disease (ACD) and occasionally, risk of thromboembolism is reported and digestive bleeding may cause death $(7,11-13)$. These clinical/hematological signs have a frequency of $4.9 \%$ in orally-transmitted ACD outbreaks (14), although higher values were described in some cases $(12,13)$. Moreover, the association between anemia and thrombocytopenia in the ACD was already envisioned by Carlos Chagas in 1909 (1).

The knowledge of immunological events that occur during $\mathrm{ACD}$ are mainly based on studies using murine models. Trypanosoma cruzi experimental infection leads to pathogen-associated molecular patterns (PAMPs) activation in macrophages and dendritic cells with IL-12 secretion. Furthermore, synthesis of interferon- $\gamma$ (IFN- $\gamma$ ), tumor necrosis factor- $\alpha$ (TNF- $\alpha$ ), and nitric oxide (NO) by macrophages contributes to parasite clearance (15). In a mouse model of T. cruzi oral infection with the Tulahuén strain, it was shown that the major source of TNF in infected tissues are macrophages and high levels of this cytokine are associated to cardiac, hepatic and spleen injuries as well as toxic shock in infected BALB/c $(16,17)$. IL-6 is also involved in host protective response since IL-6-/- mice presented 3-fold higher parasitemia and died earlier than wild-type T. cruzi infected animals, by the subcutaneous route (18). Interestingly, Th1 cytokines are involved in an intense crosstalk between immune and hemostatic systems. Acute inflammation, as a response of an infection can modulate the systemic activation of the coagulation cascade and impair physiological anticoagulant pathways (19-22).

Tissue factor (TF), the integral transmembrane protein that initiates coagulation, is strongly induced by pro-inflammatory cytokines and $\mathrm{C}$ reactive protein on monocytes, fibroblasts and endothelial cells surface allowing further interaction with factor VII to form the complex TF-factor-VIIa, ultimately resulting in fibrin formation $(19,23)$. Under normal conditions, cells in direct contact with circulating blood do not express physiologically active TF (24). The traditional coagulation cascade includes intrinsic and extrinsic pathways that lead to the activation of different coagulation factors converging at the activation of factor X to factor Xa. Factor Xa forms a complex with factor $\mathrm{Va}$ to activate prothrombin into thrombin. Thrombin then converts fibrinogen to a fibrin network forming the clot (22).

Baboons lethally challenged with Escherichia coli and infused with recombinant antithrombin (protease inhibitor of thrombin and factor $\mathrm{Xa}$ ) at high concentrations, had lower IL-6 and IL8 plasma levels and the mortality was markedly reduced (25). Furthermore, blockade of IL-6 with a monoclonal antibody, in a primate model of sepsis, attenuated the LPS-induced coagulation (26). This effect was independent of TNF, since abrogation of this cytokine with recombinant TNF receptor IgG fusion protein or a neutralizing TNF antibody in healthy humans or LPS injected chimpanzees had no effect in coagulation activation $(26,27)$. To the best of our knowledge, there are no studies focusing on the inflammatory and hematological crosstalk as well as their mechanisms in oral ACD. The few studies addressing this interaction in Chagas disease in literature focus on chronic T. cruzi infection and have controversial results regarding the existence of a prothrombotic status in T. cruzi-infected patients (28-30).

Here, by using a pre-established mouse model of oral ACD, we demonstrate that infection leads to a decrease in platelet count, increased bleeding and coagulation time, mainly in the peak of parasitemia. Importantly, circulating IL-6 levels seem to be involved in these hematological changes during oral T. cruzi infection. This information may help elucidating the mechanism of oral $\mathrm{ACD}$ pathogenesis and provide an additional view on the interaction between inflammation and coagulation in the context of infectious diseases.

\section{MATERIALS AND METHODS}

\section{Animals and Infection}

Male BALB/c mice were obtained from ICTB Oswaldo Cruz Foundation animal facilities (Brazil) and maintained in SPF conditions. Mice (6-8 weeks old) were infected via oral cavity by pipetting 50 all of excreta into their mouth with $5 \times 10^{4}$ T. cruzi insect-vector (Triatoma infestans)-derived metacyclic forms (Tulahuén strain, TcVI). A different group of mice received the same number of trypomastigotes by the subcutaneous route (SC) after a single inoculation in the dorsal region. Before the infection, mice were maintained starving $4 \mathrm{~h}$ and at least $15 \mathrm{~min}$ after inoculation.

\section{Ethics Statement}

This study was performed in strict accordance with the recommendations in the Guide for the Care and Use of Laboratory Animals of the Brazilian National Council of Animal Experimentation and the Federal Law 11.794 (10/2008). The Institutional Ethics Committee for Animal Research of the Oswaldo Cruz Foundation (CEUA-FIOCRUZ, License: L028/2016) approved all the procedures used in this study.

\section{Parasitemia}

Parasitemia was detected at different dpi by counting trypomastigotes in $5 \mu \mathrm{L}$ of tail blood and parasite number was calculated using the Pizzi-Brener method. 


\section{Cytometric Bead Array (CBA)}

Mice were anesthetized, bled by cardiac puncture and euthanized by exsanguination at $3,7,14,21,24$, and 28 dpi. Each bleeding point represents one mouse. To measure IL-6, IFN- $\gamma$, and TNF- $\alpha$ cytokines in the serum, we used the BD Mouse Th1/Th2/Th17 Cytokine CBA kit (BD Biosciences, USA). The assays were performed according to manufacturer's instructions. Sera were stored frozen at $-70^{\circ} \mathrm{C}$ until used.

\section{Blood Cell Analysis}

The mice were anesthetized and blood was collected into EDTA BD microteiner ${ }^{\circledR}$ tube by cardiac puncture. Blood cell count was automatically determined using the Poch 100- iV DIFF hematology analyzer (Sysmex, Japan).

\section{Clotting Assays and Measurements of Coagulation Factors}

Activated Partial Thromboplastin Time (aPTT) and Prothrombin time (PT) were evaluated on a STart 4 stagocoagulometer (DiagnosticaStago, USA). For the aPTT, plasma $(50 \mu \mathrm{L})$ was incubated in the coagulometer for $5 \mathrm{~min}$ at $37^{\circ} \mathrm{C}$. Then, $50 \mu \mathrm{L}$ of pre-warmed aPTT reagent (STA PTT; DiagnosticaStago, France) was added and further incubated for $2 \mathrm{~min} \mathrm{CaCl}_{2}(50 \mu \mathrm{L}$ at $25 \mathrm{mM})$ was added to start reactions. For determining the PT, plasma $(50 \mu \mathrm{L})$ was incubated in the coagulometer for $5 \mathrm{~min}$ at $37^{\circ} \mathrm{C}$. Then, $100 \mu \mathrm{L}$ of the $\mathrm{PT}$ reagent (NEOplastine CI plus; DiagnosticaStago, France) was added. Time for clot formation was recorded in duplicates.

Serum levels of coagulation factors (FV, FVII, FVIII, and APC) and D-dimer were determined using commercial enzyme linked immunoabsorbent assay (ELISA) kits according to manufacturer's protocol (ElabScience Biotechnology, China).

\section{Tail Bleeding Assay}

Bleeding propensity was evaluated as previously described (31). Mice were anesthetized with intramuscular xylazin (16 $\mathrm{mg} / \mathrm{kg}$ ) and ketamine $(100 \mathrm{mg} / \mathrm{kg})$. After $15 \mathrm{~min}$, the distal $2 \mathrm{~mm}$ segment of the tail was removed and immediately immersed in $40 \mathrm{~mL}$ distilled water warmed to $37^{\circ} \mathrm{C}$ during exactly $30 \mathrm{~min}$. The samples were properly homogenized and the absorbance was determined at $540 \mathrm{~nm}$ in order to estimate the hemoglobin content.

\section{Anti-IL6R and Anti-TNF Treatment}

Orally infected $\mathrm{BALB} / \mathrm{c}$ mice were treated intraperitoneally with a monoclonal antibody against the interleukin-6 receptor (IL-6R) $\left(8 \mathrm{mg} / \mathrm{kg}\right.$, Tocilizumab, Actemra ${ }^{\circledR}$, Roche, Switzerland), IgG control antibody $(8 \mathrm{mg} / \mathrm{kg}$, chrompure IgG Jackson Immunoresearch Labs, USA) or with a chimeric anti-TNF protein $\left(0.83 \mathrm{mg} / \mathrm{Kg}\right.$, Etanercept Enbrel ${ }^{\circledR}$, Wyeth Pharmaceuticals, USA). The treatment began at the 14 dpi with $48 \mathrm{~h}$ subsequent doses in the case of anti-IL-6R antibody or IgG control antibody and with another dose at $18 \mathrm{dpi}$ for the anti-TNF reagent. The control group received normal saline solution at the same volume $(100 \mu \mathrm{L})$ and frequency as described for orally infected mice.

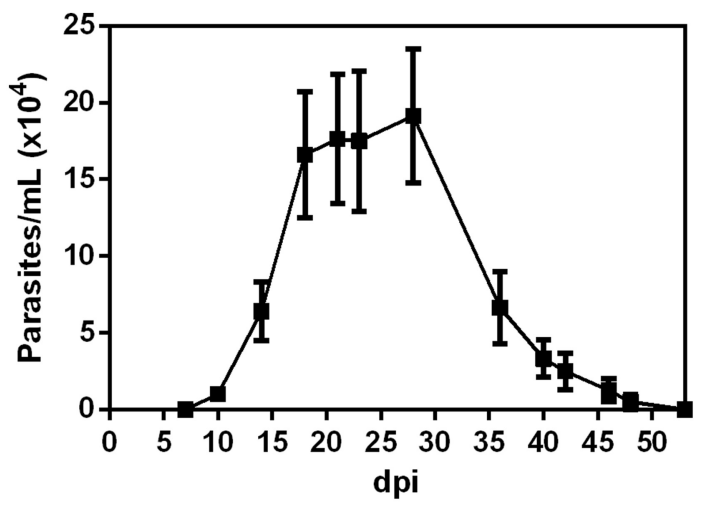

FIGURE 1 | Parasitemia development. Male BALB/c mice were infected with 5 $\times 10^{4}$ insect-derived metacyclic forms of $T$. cruzi within the oral cavity. Parasitemia (mean and SEM) was assessed during the acute phase and is expressed as parasites per milliliter. Parasites were counted by light microscopy and parasitemia calculated by the Pizzi-Brener method. n: $7 \mathrm{dpi}=$ 21,10 , and $14 \mathrm{dpi}=15,18 \mathrm{dpi}=18,21 \mathrm{dpi}=11,23 \mathrm{dpi}=6,28 \mathrm{dpi}=8$; $36,40,42,46,48$, and $53=4$. The total number of animals in each time point was obtained from different experiments.

\section{Statistical Analysis}

Data were subjected to the D'Agostino-Pearson normality test to determine whether they were sampled from a Gaussian distribution. If a Gaussian model of sampling was fulfilled, parametric test (one-way ANOVA with Tukey's multiple comparison test) was used. If the samples deviated from a Gaussian distribution, non-parametric test (Kruskal-Wallis with Dunn's multiple comparison test) was applied. All statistical analysis was done in GraphPad Prism 6 (GraphPad Software Inc.). $P<0.05$ were considered statistically significant.

\section{RESULTS}

\section{Increased Pro-inflammatory Cytokine Secretion Parallels Parasitemia Elevation in Acute T. cruzi Oral Infection}

We initially determined the parasitemia of BALB/c mice orally infected (OI) with $5 \times 10^{4} \mathrm{~T}$. cruzi metacyclic trypomastigotes. As shown in Figure 1, circulating parasites were first detected at $10 \mathrm{dpi}$. Furthermore, the animals showed higher numbers of parasites between 21 and $28 \mathrm{dpi}$. We next evaluated if T. cruzi infection caused transient changes in serum concentrations of pro-inflammatory cytokines. Accordingly, OI animals presented increased levels of TNF (Figure 2A), IFN- $\gamma$ (Figure 2B) and IL-6 (Figure 2C) when compared with non-infected animals (NI). During 14-24 dpi, all cytokines exhibited high levels concomitantly to the increased numbers of circulating parasites (Figure 1). In contrast, there were no statistically significant differences in concentrations of TNF, IFN- $\gamma$, and IL-6 in the initial stages of infection (3-7 dpi), when parasitemia is not detected. Statistically significant differences in the Th2 and Th17 cytokine levels were not detected (Figure S1). 


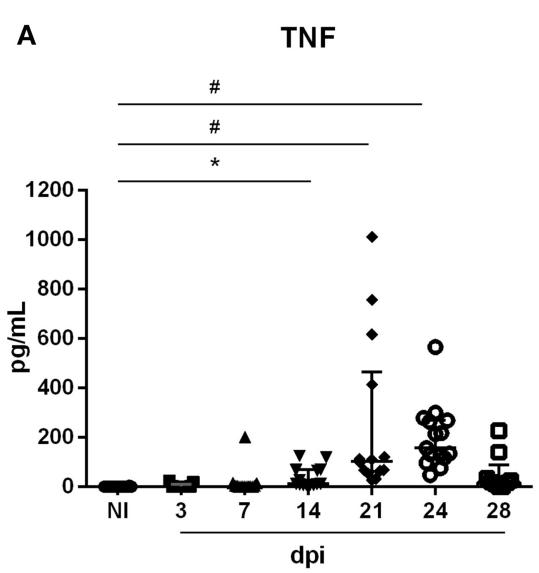

C IL-6

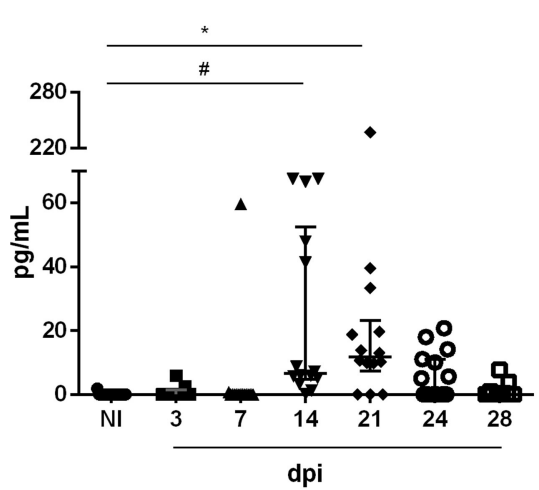

B

IFN- $\gamma$

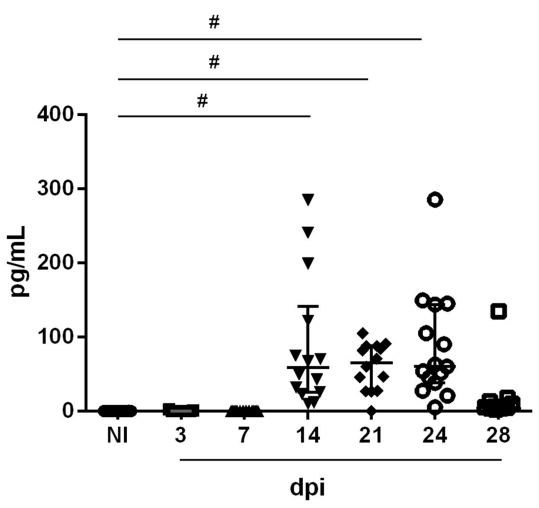

FIGURE 2 | Serum cytokine levels during oral acute T. cruzi infection. Male BALB/c mice were infected with $5 \times 10^{4}$ insect-derived metacyclic forms of T. cruzi within the oral cavity. In the course of the acute infection, serum was isolated and levels of TNF (A), IFN- $\gamma$ (B), and IL-6 (C) were quantified in non-infected (NI) and infected mice by the CBA method. Values represent the median with interquartile range for each group/day post-infection and are representative of two independent experiments. Results were analyzed using Kruskal-Wallis with Dunn's multiple comparisons test ( ${ }^{*} 0.0001<p<0.05$, \#p $\left.<0.0001\right)$. Significant differences not displayed in the graph: TNF: 3, 7 dpi $\neq 21,24$ dpi; IFN- $\gamma: 3,7$ dpi $\neq 14,21,24$ dpi; IL-6: 3 dpi $\neq 14$ dpi e 7 dpi $\neq 14,21$ dpi. n: NI = 16; 3 e 28 dpi = 9; 7,14 e 21 $\mathrm{dpi}=14 ; 24 \mathrm{dpi}=15 . \mathrm{n}: \mathrm{Nl}=16 ; 3$ and $28 \mathrm{dpi}=9 ; 7,14$, and $21 \mathrm{dpi}=14 ; 24 \mathrm{dpi}=15$.

\section{Mice Orally Infected With T. cruzi Exhibit Signs of Disseminated Intravascular Coagulation, Including Thrombocytopenia and Increased Bleeding}

We analyzed several hematological parameters in NI and OI mice on $7,14,21$, and $28 \mathrm{dpi}$. As shown in Table 1, OI induced thrombocytopenia. On day 14 and 21, the platelet counts were $775.4( \pm 62.54) \times 10^{3} / \mu \mathrm{L}$ and $840.8( \pm 83.74) \times$ $10^{3} / \mu \mathrm{L}$ for infected mice, respectively. There were no significant changes in red blood cell count, hemoglobin concentration, hematocrit and mean corpuscular volume when compared to NI. In addition, orally infected mice exhibited leukocytosis on 21 and 28 dpi (Table 1).

In order to evaluate the impact of acute infection-induced thrombocytopenia, the tail transection method was employed to evaluate the bleeding tendency. As seen in Figure 3A, OI mice showed a marked increase in bleeding at $21 \mathrm{dpi}$ when compared with the NI counterparts.

The elevated pro-inflammatory cytokine profile concomitant with the decrease in platelet count suggests that oral infection
TABLE 1 | Blood counts of non-infected (NI) and orally T. cruzi infected (OI) mice.

\begin{tabular}{lccccc}
\hline & NI & $\mathbf{7}$ & $\mathbf{1 4}$ & $\mathbf{2 1}$ & $\mathbf{2 8}$ \\
\hline WBC & $6.6 \pm 0.86$ & $9.1 \pm 0.41$ & $7.3 \pm 0.60$ & $16 \pm 2.1^{*}$ & $18 \pm 1.4^{*}$ \\
RBC & $9.8 \pm 0.27$ & $11 \pm 0.20$ & $9.5 \pm 0.21$ & $9.1 \pm 0.27$ & $10 \pm 0.46$ \\
HGB & $14 \pm 0.33$ & $16 \pm 0.35$ & $14 \pm 0.41$ & $13 \pm 0.45$ & $13 \pm 0.49$ \\
MCV & $52 \pm 0.97$ & $52 \pm 0.42$ & $49 \pm 0.47$ & $53 \pm 0.35$ & $49 \pm 0.69$ \\
HMT & $51 \pm 0.58$ & $58 \pm 1.1$ & $47 \pm 1.3$ & $48 \pm 1.6$ & $49 \pm 1.6$ \\
PLT & $1195 \pm 81.71$ & $1313 \pm 101.0$ & $775.4 \pm 62.54^{*} 840.8 \pm 83.74^{*}$ & $1282 \pm 17.44$
\end{tabular}

Blood cells were measured on the Poch 100- IV DIFF hematology analyzer. Values are presented as mean \pm SEM for each group/day post-infection and are representative of two independent experiments. Results were analyzed using the Kruskal-Wallis with Dunn's multiple comparisons test $\left(^{*} \neq \mathrm{Nl}\right.$ and $0.0001<p<0.05$. Significant differences not displayed in the graph: WBC: 7, $14 d p i \neq 21,28 d p i ; R B C: 7 d p i \neq 21 d p i$ HGB: $7 d p i$ $\neq$ 21, 28 dpi; MCV: 14 dpi f 21, 28 dpi; HMT: 7 dpi $\neq$ 14, 21 dpi. $n=5)$. HGB, total hemoglobin (g/dL); HMT, hematocrit; MCV, mean corpuscular volume (fL); PLT, number

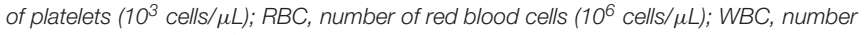
of white blood cells $\left(10^{3} \mathrm{cell} / \mathrm{s} / \mu \mathrm{L}\right)$.

may course with disseminated intravascular coagulation. In order to test this hypothesis, plasma from mice were collected and used for determination of ex vivo aPTT and PT coagulation tests. Oral infection with T. cruzi prolonged the aPTT (Figure 3B) but did 

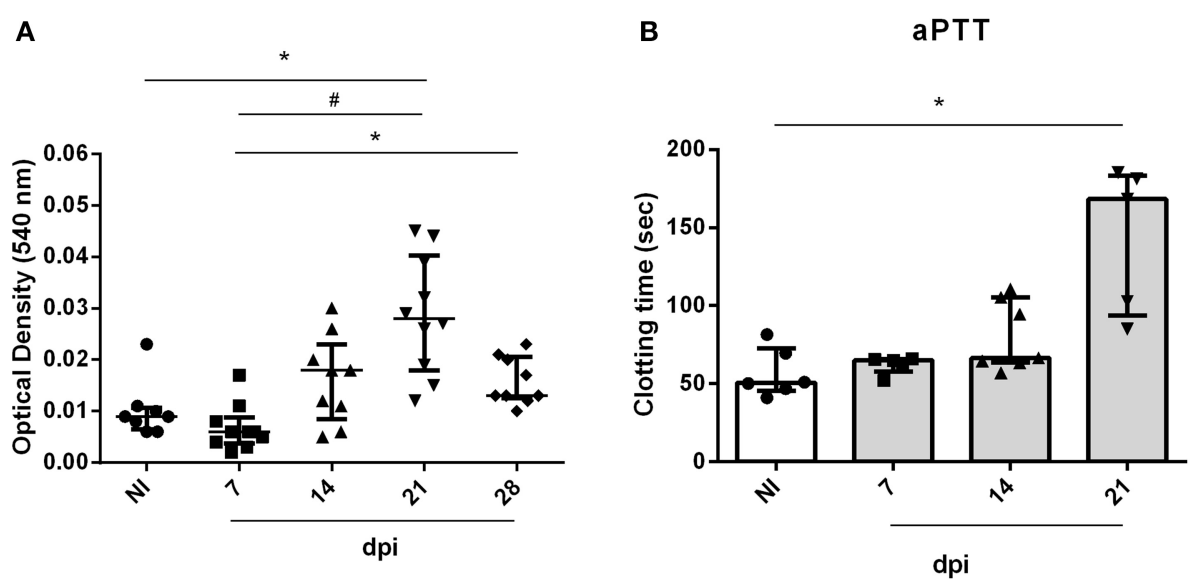

FIGURE 3 | Bleeding from the tail of BALB/c mice and ex vivo PT and aPTT measurements during oral infection. Male BALB/c mice were infected with $5 \times 10^{4}$ insect-derived metacyclic forms of $T$. cruzi (Tulahuén strain) within oral cavity. (A) Bleeding was caused by a tail transection in NI, 7, 14, and 21 dpi OI mice. Absorbance at $540 \mathrm{~nm}$ (hemoglobin concentration) was used to estimate blood loss. (B) NI or Ol plasma samples were obtained by cardiac puncture followed by addition of aPTT or PT reagent as described in the "Methods" section. Clotting time was estimated using a coagulometer. (A,B) Values represent the median with interquartile range for each group/day post-infection and are representative of two independent experiments. Results were analyzed using the Kruskal-Wallis with Dunn's multiple comparisons test $\left({ }^{*} 0.0001<p<0.05\right.$, $\left.\# p<0.0001\right)$.

TABLE 2 | Serum contents of D-dimer during acute phase of oral T. cruzi infection.

Group Mice with D-dimer $>0 \mathrm{ng} / \mathrm{mL}$

$\begin{array}{ll}\mathrm{Nl} & 0 / 6 \\ 7 \mathrm{dpi} & 0 / 5 \\ 14 \mathrm{dpi} & 3 / 6 \\ 21 \mathrm{dpi} & 2 / 6\end{array}$

Male BALB/C mice were infected with $5 \times 10^{4}$ insect-derived metacyclic forms of $T$. cruzi within the oral cavity. NI or Ol sera were obtained by cardiac puncture and used to measure levels of D-dimer by ELISA. The mean and SEM of animals with detectable levels of D-dimer were $25.7 \pm 7.59$ and $45.1 \pm 11.0$ for 14 and $21 \mathrm{dpi}$, respectively.

not affect the PT (data not show). This is compatible with a derangement in the intrinsic pathway of the coagulation cascade.

Comparison of the coagulation factor levels between NI and OI showed statistically significant differences for FV, FVII, and FVIII (Figure S2) with a consumption of FVIII at 14 dpi. DDimer, a fibrin degradation product that marks fibrin generation, degradation and reflects the turnover of the coagulation system, was also measured in NI and OI. The concentration of this biomarker was detected on 14 and $21 \mathrm{dpi}$ in OI (Table 2).

\section{Blocking of IL-6 Signaling Prevents Hematological Changes in the Murine Model of T. cruzi Oral Infection}

Oral infected mice had higher pro-inflammatory cytokine serum levels, especially between 14 and 24 dpi (Figure 2). Therefore, we hypothesized that blockade of IL-6R or soluble TNF could attenuate hemostatic changes observed in OI mice. To test this hypothesis, we treated OI mice with Tocilizumab (T), a monoclonal antibody that targets IL-6 signaling by competing for IL-6R (Figure 4A) or with a quimeric anti-TNF protein, etanercept (Enbrel ${ }^{\circledR}$ ) (Figure S3A). Both treatments started at 14 dpi. Treated OI mice group $(\mathrm{OI}+\mathrm{T})$ had a significant drop in bleeding compared with vehicle alone (saline) $\mathrm{OI}+\mathrm{V}$ (Figure 4B). Moreover, OI+T had lower aPTT than $\mathrm{OI}+\mathrm{V}$ and $\mathrm{OI}+$ isotype and showed no significant differences between noninfected controls (NI+V or NI+T) (Figure 4C). In contrast, values recorded for aPTT and bleeding assays remained unaltered after anti-TNF treatment (Figures S3B,C). These results suggest that blocking the IL-6R attenuates changes in the hemostatic system under T. cruzi oral infection whereas TNF blockade did not influence those alterations.

\section{Hematological Disturbances Are Also Observed in Subcutaneously Infected Mice}

Orally infected mice showed hemostatic alterations in the acute phase. However, we wondered whether these changes were related to the oral transmission or with $T$. cruzi presence in the bloodstream. To answer this point, mice were infected with the same inoculum by the SC route. As demonstrated in Figure 5, SC infected mice also showed a significant increase in aPTT (Figure 5B) but not in bleeding tendency or PT (Figures 5A,C). Unlike OI mice, changes in aPTT of SC animals started at $14 \mathrm{dpi}$, prior to changes in OI animals (21 dpi).

At the SC route, infection killed all animals between 15 and $16 \mathrm{dpi}$.

\section{DISCUSSION}

Previous studies indicate a relationship between inflammation and coagulation in infection $(20,21)$. Some patients with oral ACD present symptoms related to hemostatic alterations such as facial and lower limbs edema, minor bleeding manifestations, most commonly from nose, skin petechiae or bruising and risk 

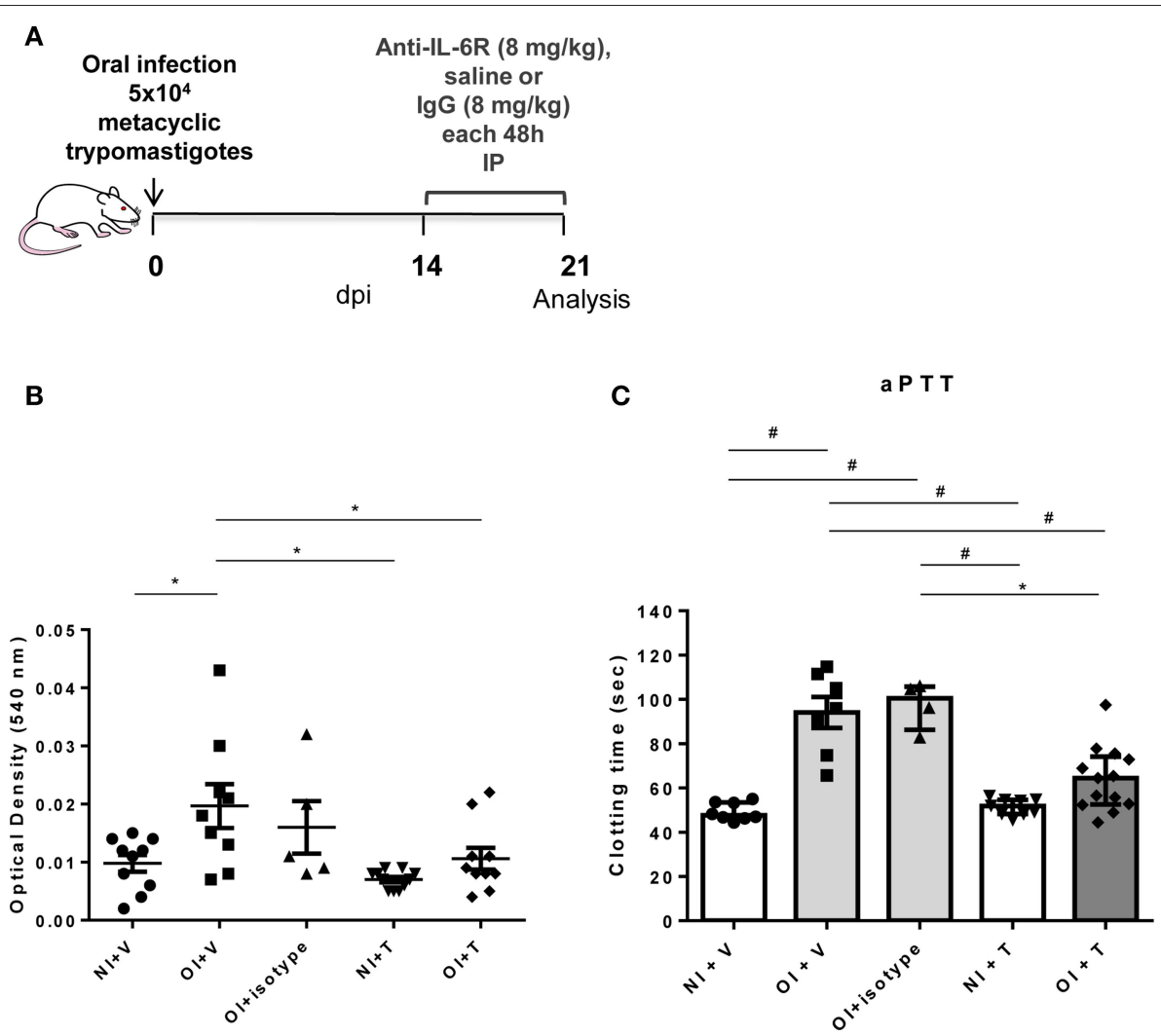

FIGURE 4 | Experimental design, coagulation test aPTT and tail bleeding assay in $\mathrm{NI}+\mathrm{V}, \mathrm{OI}+\mathrm{V}, \mathrm{Ol}+$ isotype, $\mathrm{NI}+\mathrm{T}$ and $\mathrm{OI}+\mathrm{T}$ mice. (A) Male BALB/c mice were infected with $5 \times 10^{4}$ insect-derived metacyclic forms of T. cruzi (Tulahuén strain) within the oral cavity. Anti-IL6R or lgG treatment began after 14 dpi and was performed in each $48 \mathrm{~h}$. (B) Bleeding was caused by a tail transection in $\mathrm{NI}+\mathrm{Vehicle}(\mathrm{NI}+\mathrm{V})$, Ol+V, Ol+isotype, $\mathrm{NI}+$ treatment $(\mathrm{NI}+\mathrm{T})$ and $\mathrm{Ol}+\mathrm{T}$. Absorbance at $540 \mathrm{~nm}$ (hemoglobin concentration) was used to estimate blood loss. (C) $\mathrm{NI}+\mathrm{V}$, OI+V, Ol+isotype, $\mathrm{NI}+\mathrm{T}$ and $\mathrm{Ol}+\mathrm{T}$ plasma were obtained by cardiac puncture followed by addition of the aPTT reagent as described in the "Methods" section. Clotting time was estimated using a coagulometer. (B,C) Values are presented as mean \pm SEM for each group/day post-infection and are representative of three independent experiments. Results were analyzed using one way ANOVA with Tukey's multiple comparisons test $\left({ }^{*} 0.0001<p<0.05 ; \# p<0.0001\right)$.

of thromboembolism $(7,11-13)$ indicating the need of exploring the crosstalk between immune and hemostatic systems. In the present study, we examined if the systemic inflammation led to hemostatic abnormalities in oral ACD and how blocking of IL-6 signaling pathway can modulate these changes.

We found that OI mice had significantly higher TNF, IL-6, and IFN- $\gamma$ circulating levels than controls, thus demonstrating that T. cruzi infection leads to a potent pro-inflammatory systemic response. This is consistent with previous data showing that Tulahuén strain of T. cruzi induces TNF and IFN- $\gamma$ production in BALB/c and C57BL/6 following subcutaneous (32) or OI (16). Moreover, high levels of TNF are involved in the toxic shock seen in IL-10-deficient mice infected intraperitoneally with 50 blood trypomastigotes of the Tulahuén strain of T. cruzi (33) as well as in cardiac, hepatic and spleen injury $(16,17)$. IFN- $\gamma$ and IL-6 control parasite multiplication and confers host resistance $(18,34,35)$. Furthermore, chronic patients with Chagas disease have elevated circulating levels of IL- 6 when compared to healthy individuals $(29,36)$.

Interestingly, proinflammatory cytokines play a central role in the differential effects upon the coagulation and fibrinolysis pathways. TF is strongly induced after inflammatory stimuli mainly on monocytes and endothelial cells (23). Cytokines that have the ability to increase TF expression are TNF, IL-1 $\beta$, IL6 , IFN- $\gamma$ and the chemokine CCL2 $(19,37)$. Injection of low doses of LPS in healthy volunteers induced endotoxemia and TF mRNA had a 125-fold increase in whole blood cells (38). Blocking IL-6 with a monoclonal antibody in a primate model of sepsis, largely prevented LPS-induced coagulation activation once decreased significantly levels of prothrombin fragment $1+2$ $(\mathrm{F} 1+2)$ and thrombin-antithrombin complex (26). Contrarily, the same treatment in humans did not reduce LPS-induced TF mRNA or plasma concentrations of the same markers of coagulation activation showing that results obtained from primates may not automatically be transferable into humans. IL6 is also involved in platelet thrombogenicity, once after addition of this cytokine to whole blood samples of healthy individuals, a marked spreading and clumping of the platelets was induced indicating an hyper-activation state (39).

Although the coagulation alterations mentioned above have been demonstrated to occur in vivo as a general response to proinflammatory stimuli, it is likely that other hematological changes 
A

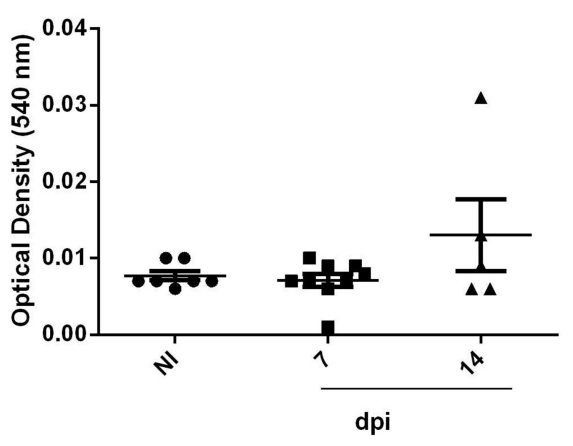

C

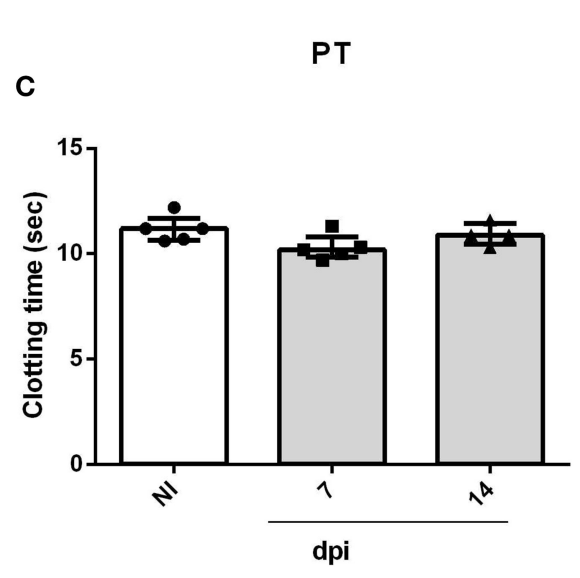

B aPTT

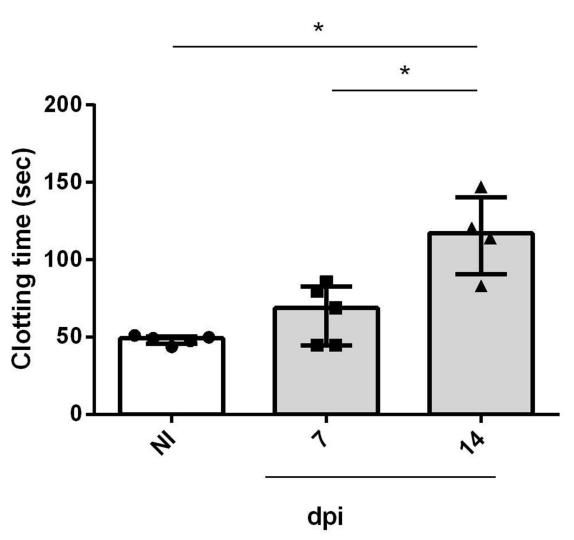

FIGURE 5 | Bleeding from the tail and ex vivo PT and aPTT measurements of BALB/c mice during subcutaneous infection. Male BALB/c mice were subcutaneously infected with $5 \times 10^{4}$ culture-derived T. cruzi trypomastigotes (Tulahuén strain). (A) Bleeding was caused by a tail transection in NI, 7 and 14 dpi SC mice. Absorbance at $540 \mathrm{~nm}$ (hemoglobin concentration) was used to estimate blood loss. (B,C) NI or SC plasma samples were obtained by cardiac puncture followed by addition of aPTT or PT reagent. Clotting time was estimated using a coagulometer. (A-C) Values are presented as mean \pm SEM for each group/day post-infection and are representative of one experiment. Results were analyzed using one way ANOVA with Tukey's multiple comparisons test $\left({ }^{\star} 0.0001<p<0.05\right)$.

may occur. Trypanosoma cruzi infection in humans is associated with anemia, thrombocytopenia and leukocytosis, mainly during the acute phase of disease $(1,40)$. Studies in inoculated mice with different $T$. cruzi strains also revealed anemia and thrombocytopenia during the acute phase of infection $(41,42)$. The mechanisms underlying these changes in blood count are not fully understood, but bone marrow suppression in hemopoiesis may be involved (42). In a second vein, the parasite transsialidase may induce the accelerated clearance of the platelets after depleting their sialic acid content that could lead to the thrombocytopenia observed during ACD (43). In a review of 31 published studies concerning hematological alterations in nonhuman hosts infected with T. cruzi (44), half of the studies reported anemia. However, we did not find significant changes in the erythrogram. An explanation could be the different route of inoculation.

Additionally, increased numbers of leukocytes were observed on 21 and $28 \mathrm{dpi}$. This alteration is also described in patients and in animal models (44-47). At $21 \mathrm{dpi}$, when platelet counts were still significantly lower, the normal platelet plug formation was affected as ascertained by tail bleeding assay. Notwithstanding, thrombocytopenia in humans with functional platelets generally does not induce or induces only minor bleeding symptoms, with the exception of lifethreatening hemorrhages $(48,49)$. By contrast, mice with severe thrombocytopenia and inflammation resulted in spontaneous hemorrhage in different organs (50). Also at $21 \mathrm{dpi}$, beyond reduction in platelet plug formation, coagulation changes were seen with increased aPTT. Interestingly, production of D-dimer was evaluated and was detected at 14 and $21 \mathrm{dpi}$ and FVIII levels were very low at $14 \mathrm{dpi}$.

Taken together, the disturbances mentioned above characterize the clinical syndrome of disseminated intravascular coagulation (DIC). This syndrome corresponds to a derangement of hemostasis with hemorrhage being the most common presentation consisting of widespread production of thrombin, which in turn leads to microvascular thrombosis, organ failure, and a consumptive coagulopathy related to a systemic 

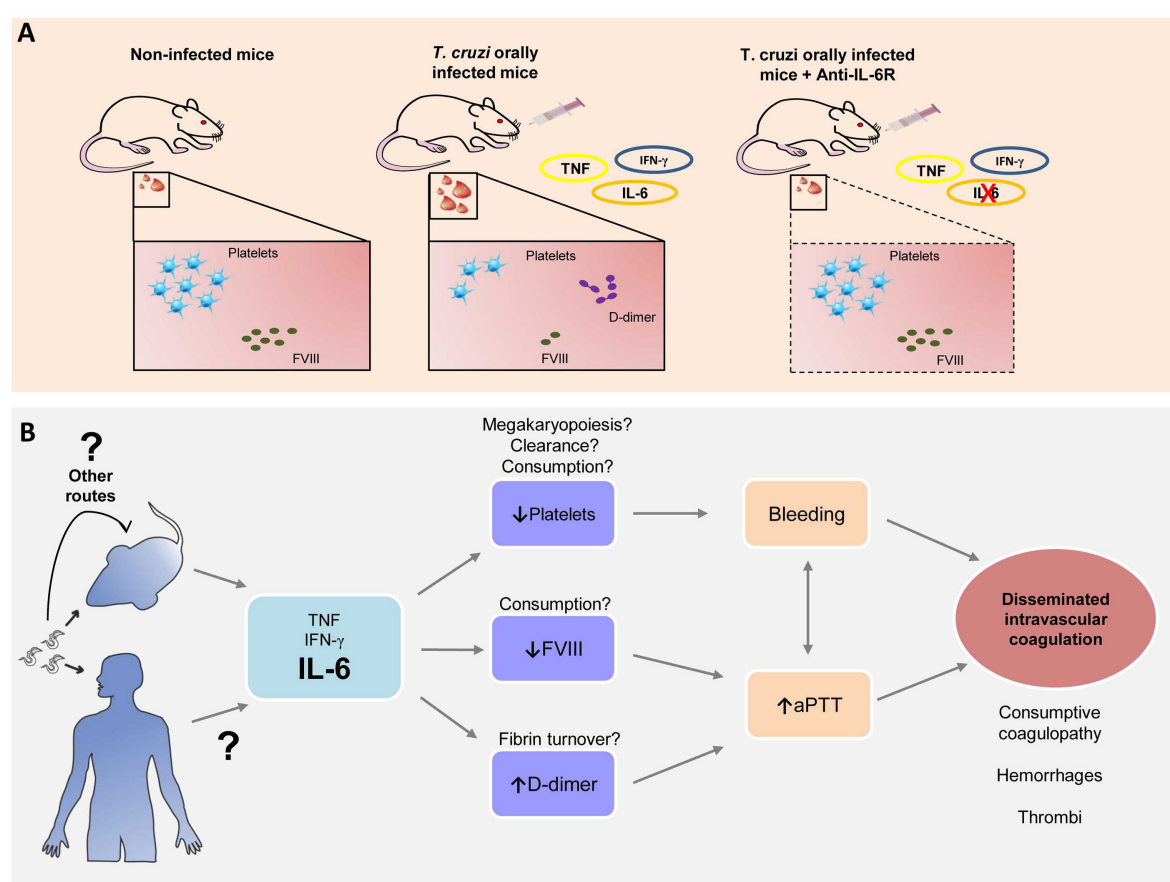

FIGURE 6 | Trypanosoma cruzi oral infection causes hemostatic derangement linked to a systemic inflammation. (A) Trypanosoma cruzi orally infected mice have thrombocytopenia, Factor VIII depletion and increased D-dimer levels, linked to a systemic inflammation. Blocking of IL-6 signaling restores normal hemostasis. (B) Hypothesis: Acute T. cruzi infection leads to increase of pro-inflammatory cytokines. IL-6 is associated with a decrease with platelet count, possibly due to megakaryopoiesis disturbances, platelet clearance and/or consumption; reduction in serum FVIII levels and high levels of D-dimer related to fibrin turnover. Altogether these processes are involved in the increase of bleeding tendency and aPTT, signs of disseminated intravascular coagulation that leads to microhemorrhages and microthrombi as previously reported $(7,13,16)$.

inflammation (19). In fact, we previously showed formation of thrombotic masses in the liver of OI mice (16). Patients with DIC have higher IL-6 levels with the cytokine increase being paralleled by the severity of the disease (51). Therefore, we hypothesized that blockade of the IL- 6 signaling would protect or minimize the hematological disturbances observed at $21 \mathrm{dpi}$. Yet, there was an impressive reduction in inflammation associated changes comprising significant reduction in coagulation time, aPTT and bleeding time. Both did not differ from control levels. However, anti-TNF treatment did not change these parameters, suggesting that TNF is not affecting directly the coagulation cascade, as observed in sepsis $(26,27)$.

Thus, based on these early findings, targeting the immune system, more specifically IL-6R, during the acute phase of oral infection, can prevent a hemostatic derangement (Figure 6A). Since any long-term benefits and liabilities of the intervention still remain uncertain, it will be interesting to explore whether long-term benefits are also gained in our model of T. cruzi oral infection.

This study instigates many questions to explore. The hematological disturbances also develop in a parenteral route of transmission such as subcutaneously, suggesting that inflammatory response to parasite presence in the blood triggers this process. Moreover, whether there is an influence of the genetic variability of the parasite, i.e.,
T. cruzi DTUs (named as TcI to TcVI) correlated with more severe hematological changes. TcI, TcII, TcIII, TcIV, and TcVI genotypes had been reported in oral outbreaks (52-54) even though in the Brazilian Amazon prevails TcI (55) and in this study we used Tulahuén strain (TcVI). Ultimately, if there is any dysregulation of megakaryopoiesis leading to thrombocytopenia, changes in platelet clearance or consumption, deep alterations in fibrinolytic system remains undetermined (Figure 6B).

In conclusion, we show for the first time that oral ACD promotes a hemostatic derangement linked to systemic inflammation. This process is associated to low platelet count, bleeding and increased coagulation time, in parallel with high parasitemia. Blocking IL-6 signaling pathway ameliorates all these changes. Our studies open a new paradigm of looking to the hemostatic system when evaluating a patient infected with T. cruzi and suggest that translation of these results may be possible in the near future.

\section{ETHICS STATEMENT}

This study was carried out in accordance with the recommendations of the Guide for the Care and Use of Laboratory Animals of the Brazilian National Council of 
Animal Experimentation and the Federal Law 11.794 (10/2008) Institutional Ethics Committee for Animal Research of the Oswaldo Cruz Foundation (CEUA-FIOCRUZ). The protocol was approved by CEUA-FIOCRUZ, License: L-028/16.

\section{AUTHOR CONTRIBUTIONS}

Conceived and designed the experiments: DA, RM, and JdM. Performed the experiments: DA, AM-D-S, MR, BM, CM, and DF-d-O. Analyzed the data: DA, WS, and JdM. Wrote the manuscript: DA, WS, RM, and JdM. All authors read and revised the manuscript.

\section{FUNDING}

This work was supported by National Institute of Science and Technology on Neuroimmunomodulation (INCTNIM), Oswaldo Cruz Foundation, the Brazilian National Council for Development of Science and Technology (CNPq),

\section{REFERENCES}

1. Chagas C, Chagas C. Nova tripanozomiaze humana: estudos sobre a morfolojia e o ciclo evolutivo do Schizotrypanum cruzi n. gen., n. sp., ajente etiolojico de nova entidade morbida do homem. Mem Inst Oswaldo Cruz. (1909) 1:159-218. doi: 10.1590/S0074-02761909000200008

2. Moraes-Souza H, Ferreira-Silva MM. O controle da transmissão transfusional. Rev Soc Bras Med Trop. (2011) 44(suppl 2):64-7. doi: 10.1590/S0037-86822011000800010

3. Márquez E, Crespo M, Mir M, Pérez-Sáez MJ, Quintana S, Barbosa F, et al. Chagas' disease and kidney donation. Nefrologia. (2013) 33:128-33. doi: 10.3265/Nefrologia.pre2012.Sep.11636.

4. Carlier Y, Sosa-Estani S, Luquetti AO, Buekens P. Congenital chagas disease: an update. Mem Inst Oswaldo Cruz. (2015) 110:363-8. doi: 10.1590/0074-02760140405

5. Hofflin JM, Sadler RH, Araujo FG, Page WE, Remington JS. Laboratoryacquired chagas disease. Trans $R$ Soc Trop Med Hyg. (1987) 81:437-40. doi: 10.1016/0035-9203(87)90162-3

6. Pereira KS, Schmidt FL, Guaraldo AMA, Franco RMB, Dias VL, Passos LAC. Chagas' disease as a foodborne illness. J Food Prot. (2009) 72:441-6. doi: 10.4315/0362-028X-72.2.441

7. Shikanai-Yasuda MA, Carvalho NB. Oral transmission of chagas disease. Clin Infect Dis. (2012) 54:845-52. doi: 10.1093/ cid/cir956

8. Coura JR. The main sceneries of chagas disease transmission. the vectors, blood and oral transmissions - a comprehensive review. Mem Inst Oswaldo Cruz. (2014) 110:277-82. doi: 10.1590/0074-0276140362

9. Santos VRC dos, Meis J de, Savino W, Andrade JAA, Vieira JR dos S, Coura JR, et al. Acute chagas disease in the state of pará, Amazon region: is it increasing? Mem Inst Oswaldo Cruz. (2018) 113:e170298. doi: 10.1590/0074-02760170298

10. Rassi A, Rassi A, Marin-Neto JA. Chagas disease. Lancet. (2010) 375:1388-402. doi: 10.1016/S0140-6736(10)60061-X

11. Souza PFP de, Pine RCD, Ramos FL de P, Pinto AY das N. Atrial fibrillation in acute chagas disease acquired via oral transmission: a case report. Rev Soc Bras Med Trop. (2018) 51:397-400. doi: 10.1590/0037-8682-0296-2017

12. Pinto AY, das N, Valente SA, Valente V, da C, Ferreira Junior AG, et al. Fase aguda da doença de chagas na Amazônia brasileira: estudo de 233 casos do Pará, Amapá e Maranhão observados entre 1988 e 2005. Rev Soc Bras Med Trop. (2008) 41:602-14. doi: 10.1590/S0037-86822008000600011

13. Pamplona De Góes Cavalcanti L, Rolim DB, Da Justa R, Neto P, Lima DC, Vilar F, et al. Microepidemia de doença de chagas aguda por transmissão oral no Ceará. Cad Saúde Colet, Rio Janeiro. (2009) 17:911-21.
Coordination for the Improvement of Higher Education Personnel (CAPES), State of Rio de Janeiro Foundation for Funding Research (FAPERJ) and the Mercosur Program for Structural Convergence (FOCEM).

\section{ACKNOWLEDGMENTS}

The authors would like to thank Dr. Ernesto de Meis (in memoriam) for conceiving the first study that gave rise to the project, Dr. Daniella Mizurini for first guidance with hematological tests, Dr. Igor Lima for clarifying some statistical doubts and the Program for Technological Development in Tools for Health-PDTIS-FIOCRUZ for the use of its facilities.

\section{SUPPLEMENTARY MATERIAL}

The Supplementary Material for this article can be found online at: https://www.frontiersin.org/articles/10.3389/fimmu. 2019.01073/full\#supplementary-material

14. Filigheddu MT, Górgolas M, Ramos JM. Enfermedad de chagas de transmisión oral. Med Clin (Barc). (2017) 148:125-31. doi: 10.1016/j.medcli.2016.10.038

15. Silva JS, Vespa GN, Cardoso MA, Aliberti JC, Cunha FQ. Tumor necrosis factor alpha mediates resistance to Trypanosoma cruzi infection in mice by inducing nitric oxide production in infected gamma interferon-activated macrophages. Infect Immun. (1995) 63:4862-7.

16. Barreto-de-Albuquerque J, Silva-dos-Santos D, Pérez AR, Berbert LR, Santana-van-Vliet E de, Farias-de-Oliveira DA, et al. Trypanosoma cruzi infection through the oral route promotes a severe infection in mice: new disease form from an old infection? PLoS Negl Trop Dis. (2015) 9:e0003849. doi: 10.1371/journal.pntd.0003849

17. Andrade ZA, Andrade SG, Correa R, Sadigursky M, Ferrans VJ. Myocardial changes in acute Trypanosoma cruzi infection. ultrastructural evidence of immune damage and the role of microangiopathy. Am J Pathol. (1994) 144:1403-11.

18. Gao W, Pereira MA. Interleukin-6 is required for parasite specific response and host resistance to Trypanosoma cruzi. Int J Parasitol. (2002) 32:167-70. doi: 10.1016/S0020-7519(01)00322-8

19. Levi M, Keller TT, Van Gorp E, Ten Cate H. Infection and inflammation and the coagulation system. Cardiovas Res. (2003) 60:26-39. doi: 10.1016/S0008-6363(02)00857-X

20. Azeredo EL de, Monteiro RQ, de-Oliveira Pinto LM. Thrombocytopenia in dengue: interrelationship between virus and the imbalance between coagulation and fibrinolysis and inflammatory mediators. Med Inflamm. (2015) 2015:1-16. doi: 10.1155/2015/313842

21. van der Poll T, Boer JD de, Levi $M$. The effect of inflammation on coagulation and vice versa. Curr Opin Infect Dis. (2011) 24:273-8. doi: 10.1097/QCO.0b013e328344c078

22. Francischetti IMB, Seydel KB, Monteiro RQ. Blood coagulation, inflammation, and malaria. Microcirculation. (2008) 15:81-107. doi: 10.1080/10739680701451516

23. Osterud B, Bjorklid E. Tissue factor in blood cells and endothelial cells. Front Biosci (Elite Ed). (2012) 4:289-99. doi: 10.2741/e376

24. Butenas S, Mann KG. Active tissue factor in blood? Nat Med. (2004) 10:11556. doi: $10.1038 / \mathrm{nm} 1104-1155 \mathrm{~b}$

25. Minnema MC, Chang AC, Jansen PM, Lubbers YT, Pratt BM, Whittaker BG, et al. Recombinant human antithrombin III improves survival and attenuates inflammatory responses in baboons lethally challenged with Escherichia coli. Blood. (2000) 95:1117-23.

26. van der Poll T, Levi M, Hack CE, ten Cate H, van Deventer SJ, Eerenberg AJ, et al. Elimination of interleukin 6 attenuates coagulation activation in 
experimental endotoxemia in chimpanzees. J Exp Med. (1994) 179:1253-9. doi: 10.1084/jem.179.4.1253

27. van der Poll T, Coyle SM, Levi M, Jansen PM, Dentener M, Barbosa K, et al. Effect of a recombinant dimeric tumor necrosis factor receptor on inflammatory responses to intravenous endotoxin in normal humans. Blood. (1997) 89:3727-34.

28. de Melo LM, Souza GE, Valim LR, Moreira LF, Damico EA, da Rocha TR, et al. Study of pro-thrombotic and pro-inflammatory factors in chagas cardiomyopathy. Arq Bras Cardiol. (2010) 95:655-62. doi: 10.1590/S0066-782X2010005000146

29. Herrera RN, de Amaya EID, Aguilar RCP, Turoni CJ, Marañón R, Berman SG, et al. Inflammatory and prothrombotic activation with conserved endothelial function in patients with chronic, asymptomatic chagas disease. Clin Appl Thromb. (2011) 17:502-7. doi: 10.1177/1076029610375814

30. Herrera RN, Díaz E, Pérez Aguilar R, Bianchi J, Berman S, Luciardi HL. Prothrombotic state in early stages of chronic Chagas' disease. Its association with thrombotic risk factors. Arch Cardiol Mex. (2005) 75 (Suppl 3):S3-38-48.

31. Ma D, Mizurini DM, Assumpção TCF, Li Y, Qi Y, Kotsyfakis M, et al. Desmolaris, a novel factor XIa anticoagulant from the salivary gland of the vampire bat (Desmodus rotundus) inhibits inflammation and thrombosis in vivo. Blood. (2013) 122:4094-106. doi: 10.1182/blood-2013-08-517474

32. Roggero E, Perez A, Tamae-Kakazu M, Piazzon I, Nepomnaschy I, Wietzerbin J, et al. Differential susceptibility to acute Trypanosoma cruzi infection in $\mathrm{BALB} / \mathrm{c}$ and $\mathrm{C} 57 \mathrm{BL} / 6$ mice is not associated with a distinct parasite load but cytokine abnormalities. Clin Exp Immunol. (2002) 128:421-8. doi: 10.1046/j.1365-2249.2002.01874.x

33. Hölscher C, Mohrs M, Dai WJ, Köhler G, Ryffel B, Schaub GA, et al. Tumor necrosis factor alpha-mediated toxic shock in Trypanosoma cruziinfected interleukin 10-deficient mice. Infect Immun. (2000) 68:4075-83. doi: 10.1128/IAI.68.7.4075-4083.2000

34. Gutierrez FRS, Mineo TWP, Pavanelli WR, Guedes PMM, Silva IS. The effects of nitric oxide on the immune system during Trypanosoma cruzi infection. Mem Inst Oswaldo Cruz. (2009) 104(Suppl 1):236-45. doi: 10.1590/S0074-02762009000900030

35. Cunha-Neto E, Nogueira LG, Teixeira PC, Ramasawmy R, Drigo SA, Goldberg AC, et al. Immunological and non-immunological effects of cytokines and chemokines in the pathogenesis of chronic chagas disease cardiomyopathy. Mem Inst Oswaldo Cruz. (2009). 104(Suppl 1):252-8. doi: 10.1590/S0074-02762009000900032

36. López L, Arai K, Giménez E, Jiménez M, Pascuzo C, Rodríguez-Bonfante C, et al. C-reactive protein and interleukin-6 serum levels increase as chagas disease progresses towards cardiac failure. Rev Esp Cardiol. (2006) 59:50-6. doi: 10.1016/S1885-5857(06)60048-0

37. Chen JP, Cosgriff TM. Hemorrhagic fever virus-induced changes in hemostasis and vascular biology. Blood Coagul Fibrinolysis. (2000) 11:461-83. doi: 10.1097/00001721-200007000-00010

38. Franco RF, Jonge E, Dekkers PE, Timmerman JJ, Spek CA, van Deventer $\mathrm{S}$, et al. The in vivo kinetics of tissue factor messenger RNA expression during human endotoxemia: relationship with activation of coagulation. Blood. (2000) 96:554-9.

39. Bester J, Pretorius E. Effects of IL-1 $\beta$, IL- 6 and IL- 8 on erythrocytes, platelets and clot viscoelasticity. Sci Rep. (2016) 6:32188. doi: 10.1038/srep32188

40. Shikanai-Yasuda MA, Lopes MH, Tolezano JE, Umezawa E, Amato Neto VBA. Doença de chagas aguda: vias de transmissão, aspectos clínicos e resposta à terapêutica específica em casos diagnosticados em um centro urbano. Rev Inst Med Trop São Paulo. (1990) 32:16-27. doi: 10.1590/S0036-46651990000100004

41. Cardoso JE, Brener Z. Hematological changes in mice experimentally infected with Trypanosoma Cruzi. Mem Inst Oswaldo Cruz. (1980) 75:97-104. doi: 10.1590/S0074-02761980000200009
42. Marcondes MCG, Borelli P, Yoshida N, Russo M. Acute Trypanosoma cruzi infection is associated with anemia, thrombocytopenia, leukopenia, and bone marrow hypoplasia: reversal by nifurtimox treatment. Microbes Infect. (2000) 2:347-52. doi: 10.1016/S1286-4579(00)00333-6

43. Tribulatti MV, Mucci J, Van Rooijen N, Leguizamón MS, Campetella O. The trans-sialidase from Trypanosoma cruzi induces thrombocytopenia during acute chagas' disease by reducing the platelet sialic acid contents. Infect Immun. (2005) 73:201-7. doi: 10.1128/IAI.73.1.201-207.2005

44. Villalba-Alemán E, Justinico DL, Sarandy MM, Novaes RD, Freitas MB, Gonçalves RV. Haematological alterations in non-human hosts infected with Trypanosoma cruzi: a systematic review. Parasitology. (2019) 146:142-60. doi: $10.1017 /$ S0031182018001294

45. Moreno EA, Araujo MA, Alarcón ME, Lugo A, Moreno SC, Borges R. Hematological and blood glucose alterations in Wistar rats with acute chagasic infection during gestation. Invest Clin. (2007) 48:187-98.

46. Dias E, Laranja FS, Miranda A, Nobrega G. Chagas' disease; a clinical, epidemiologic, and pathologic study. Circulation. (1956) 14:1035-60. doi: 10.1161/01.CIR.14.6.1035

47. Tanowitz HB, Kirchhoff LV, Simon D, Morris SA, Weiss LM, Wittner M. Chagas' disease. Clin Microbiol Rev. (1992) 5:400-19. doi: 10.1128/CMR.5.4.400

48. Neunert CE, Bright BC, Buchanan GR. Severe chronic refractory immune thrombocytopenic purpura during childhood: a survey of physician management. Pediatr Blood Cancer. (2008) 51:513-6. doi: 10.1002/pbc.21621

49. Chong BH, Ho S-J. Autoimmune thrombocytopenia. J Thromb Haemost. (2005) 3:1763-72. doi: 10.1111/j.1538-7836.2005.01376.x

50. Goerge T, Ho-Tin-Noe B, Carbo C, Benarafa C, Remold-O'Donnell E, Zhao $\mathrm{B}-\mathrm{Q}$, et al. Inflammation induces hemorrhage in thrombocytopenia. Blood. (2008) 111:4958-64. doi: 10.1182/blood-2007-11-123620

51. Seo JW, Kim HK, Lee DS, Cho HI. Clinical usefulness of plasma interleukin6 and interleukin-10 in disseminated intravascular coagulation. Korean J Lab Med. (2007) 27:83-8. doi: 10.3343/kjlm.2007.27.2.83

52. Steindel M, Kramer Pacheco L, Scholl D, Soares M, de Moraes MH, Eger I, et al. Characterization of Trypanosoma cruzi isolated from humans, vectors, and animal reservoirs following an outbreak of acute human chagas disease in Santa Catarina State, Brazil. Diagn Microbiol Infect Dis. (2008) 60:25-32. doi: 10.1016/j.diagmicrobio.2007.07.016

53. Meza SKL, Kaneshima EN, Silva S de O, Gabriel M, Araújo SM de, Gomes ML, et al. Comparative pathogenicity in Swiss mice of Trypanosoma cruzi IV from northern Brazil and Trypanosoma cruzi II from southern Brazil. Exp Parasitol. (2014) 146:34-42. doi: 10.1016/j.exppara.2014.08.014

54. Ramírez JD, Montilla M, Cucunubá ZM, Floréz AC, Zambrano P, Guhl F. Molecular epidemiology of human oral chagas disease outbreaks in colombia. PLoS Negl Trop Dis. (2013) 7:e2041. doi: 10.1371/journal.pntd.0002041

55. Monteiro WM, Margioto Teston AP, Gruendling AP, dos Reis D, Gomes ML, Marques de Araújo S, et al. Trypanosoma cruzi I and IV stocks from Brazilian Amazon are divergent in terms of biological and medical properties in mice. PLoS Negl Trop Dis. (2013) 7:e2069. doi: 10.1371/journal.pntd.0002069

Conflict of Interest Statement: The authors declare that the research was conducted in the absence of any commercial or financial relationships that could be construed as a potential conflict of interest.

Copyright (C) 2019 Antunes, Marins-Dos-Santos, Ramos, Mascarenhas, Moreira, Farias-de-Oliveira, Savino, Monteiro and de Meis. This is an open-access article distributed under the terms of the Creative Commons Attribution License (CC BY). The use, distribution or reproduction in other forums is permitted, provided the original author(s) and the copyright owner(s) are credited and that the original publication in this journal is cited, in accordance with accepted academic practice. No use, distribution or reproduction is permitted which does not comply with these terms. 